\title{
Reduced Cardiovascular Disease Deaths in 21 Western Countries 1989-91 V 2013-154: What is the UK doing Right or What is the USA doing Wrong?
}

\author{
Colin Pritchard*1, Emily Rosenorn-Lanng ${ }^{1}$, Lars Hansen² and Michael Mahmoudi ${ }^{2}$ \\ ${ }^{1}$ Research Professor, Emily Rosenorn-Lanng Research Fellow, Faculty of Health \& Social Sciences, Bournemouth University UK \\ ${ }^{2}$ Consultant Psychiatrist, Honorary Senior Lecturer, Associate Professor Michael Mahmoudi, Consultant Cardiologist, University of Southampton UK
}

*Corresponding author: Colin Pritchard, Department of Health \& Social Sciences,

Bournemouth University, UK.

Received Date: February 04, 2019

Published Date: February 14, 2019

\begin{abstract}
Objectives: To compare UK Cardiovascular Disease Deaths (CDD) with twenty Other Western Countries (OWC).

Design: Population-controlled-based study using WHO data on CDD people aged 55-74 and Age-Standardised-Death-Rates (ASDR) rates per million (pm) contrasts UK and OWC outcomes between 1989-2015 and World Bank \% GDP Expenditure-on-Health (\%GDPEH) data.
\end{abstract}

Setting: Twenty-one Western Countries.

Participants: National populations.

Outcome measures: Reduced CDD for people aged 55-74 and ASDR confidence intervals determines statistical differences between UK and OWC over the period.

Result: All countries substantially reduced CDD 55-74, highest current rates America at 3440pm, Finland 3197pm, Greece 3173 to lowest, France $1522 \mathrm{pm}$, Australia $1634 \mathrm{pm}$ and Japan $1866 \mathrm{pm}$. Previously UK was 4th highest but fell to 8th at 2524pm, significantly reducing CDD more than 15 OWC, though three had greater falls than Britain. ASDR fell substantially everywhere but the UK had second biggest reduction, significantly reducing total CDD deaths more than 15 OWC. Highest 1980-2015 average \%GDPEH was USA at $12.7 \%$, UK's $7.6 \%$ was lowest suggesting British cardiac services achieved more with proportionately less.

Conclusion: Improvements in primary and secondary prevention of cardiovascular disease occurred in every country, we speculate whether the UK success might be attributable to the Pan UK public health innovations, the National Service Framework (2000) to reduce myocardial infarction, and, National Framework for long term conditions (2005) but further research is required to identify the effective mechanisms. These results should be a morale boost for patients and their families and or all in the cardiac services, especially in the UK.

Acknowledgement: We have no vested or conflict of interests in this study. Nor was there any external funding for the project. Keywords: International Cardiovascular Disease Deaths Health Expenditure

\section{Introduction}

Cardiovascular Disease Deaths (CDD) are the largest WHO global diagnostic mortality category [1]. This population-based study compares the UK CDD outcomes between 1989-91 and 201315 with the twenty Other-Western-Countries (OWC) between 1989 and 2015. The CDD category includes ischemic heart disease, cerebrovascular disease, hypertension, rheumatic hearts disease

and arterial disease related deaths [1]. Indeed, of the 25 countries in the Organisation for Economic Co-operation \& Development (OECD) one in three deaths were cardiovascular related but there have been major improvements in the last two decades as approximately there are $50 \%$ fewer deaths from ischaemic heart disease [2]. However, there was no direct comparison between the 
UK and the other OECD countries over the time period, set within the context of a nations percentage GDP-Expenditure-on-Health (\%GDPEH), which makes this study timely CDD rates are agerelated and rise in each age-band, the highest being in the over-75's, the second highest is in people aged 55-74 [1]. Thus, reducing heart disease deaths in people aged 55-74 will make a major contribution to saving life, reducing disability and improving life-expectancy.

It is appreciated that there may be many different clinical and social reasons for the reduction in CDD; for example - improved diagnostic monitoring and surgical procedures $[3,4]$; the use of lipid lowering therapy such as statins [5,6]; improved lifestyles $[7,8]$; reducing over-work $[9,10]$; cessation of smoking in public venues $[11,12]$ invasive percutaneous intervention in patients presenting with acute coronary syndromes, as well as effective treatment of hypertension [13], diabetes and atherosclerosis [13,14]. There is a degree of debate whether public health approach, such as dietary changes, as opposed to treatment initiatives, have made the greater contribution $[7,11,14]$.

During an international study of changing patterns of neurological deaths, CDD were used as controls, as one of the two broad categories of age-related diseases [15]. It was found, that unlike major increases in brain disease deaths, CDD had fallen substantially over two decades in all the 21 liberal Western democratic countries, including the UK. Moreover, there was no statistical association between rises in neurological deaths and decreases in CDD [15]. This led to this study which asks to what extent have UK combined male and female adult (55-74) heart disease death rates fallen in comparison to the twenty Other Western Countries (OWC), using the latest WHO data, updated June 2018 [1].

It has been shown that based upon World Bank data, updated July 2018 [16], over the last 30 years the UK has had comparative chronic under-funding, having one of the lowest percentages of GDP-Expenditure-on Health (\%GDPEH) in the Western world $[16,17]$. Consequently, a direct comparison between the UK and other countries concerning the major health outcome, that ignores the relative resource issue, might be considered unreasonable. To account for this possible fiscal disadvantage, it was decided to examine CDD outcomes within the context of each nation's \%GDPHE drawn from the World Bank updated July 2018. This is a hypothesis stimulating study that asks how effective has the UK been in reducing CDD compared to the twenty OWC between 1989. 91 and 2013- 15 and what might account for the changes?

There is one working null hypothesis, that there will be no significant differences in reduced CDD between the UK and the OWC over the period 1989 to 2015.

\section{Design \& Method}

The latest WHO data is all age controlled, updated June 2018, enabling an analysis of mortality rates per million (pm) of population of people aged 55-74 years for both sexes. Along with Age-Standardised-Death-Rates (ASDR) which is the total CDD using the WHO world standard population that includes all age bands [1]. The 10th edition of the International Classification of Diseases began in 1989, for Circulatory Disease Deaths (CDD) is coded H100-199 and relates to mortality due to cerebrovascular disease, ischaemic disease, hypertension, rheumatic heart disease and arterial diseases, ensuring as uniform a categorisation as possible [1]. Hence the comparative average baseline years are 1989-91 to compare with the latest index years available the average of 201315. Germany baseline years were 1990-92 and a few countries have earlier index years, 2011-13 or 2012-14, which are noted in the tables. Each country is its own control as it is compared against its own baseline and index years, from which a ratio of change is calculated.

An inherent problem of international comparisons is the reliability of the data as well as how different health, social policies and health services influence health outcomes. Only country-specific research could resolve this latter problem. The issue of reliability of diagnosis can also be significant, but this is largely resolved as we are not focusing upon one diagnostic category but rather the global category of cardiovascular disease deaths (CDD) [1]. Furthermore, the WHO data is collected in a consistent and uniform system and is probably the most reliable and valid international data available.

\section{Socio-economic context- input}

The economic input into health care is the national percentage of Gross-Domestic-Product- Expenditure-on-Health (\%GDPEH), which is a practical indication of a nation's financial priority it affords to health from within its national budget. The data for total percentage of \%GDPEH is the combined public and private sources devoted to health and social services and drawn from the latest World Bank data, updated July 2018 [16]. It could be said that the different \%GDPEH illustrates the degree to which countries prioritise their health care, irrespective of how the services are configured, though every country has made substantial increases since 1980 [16], though it is known that the UK has one of the lowest \%GDP devoted to health of the countries reviewed [16,17]. Between 1980 and up to 2015 there were only twenty-six separate for which \%GDPEH was recorded, from which we calculate a 19802015 average \%GDPEH. Not everyone of these 26 years data was available there being missing years for Australia in 2004 and 2008, Belgium 2004, Denmark 2008, Germany 2004 and Greece for 1994, 2004 and 2008. The numbers of missing years for each country are indicated in Table 3.

\section{Statistics}

To compare any differences between UK CDD outcomes and the twenty Other Western Countries (OWC) we used the SPSS statistical package to calculate Confidence Intervals (to + or - 95\% significance) to determine any statistical significance over the period between the UK and the OWC CDD rates all controlled for population. To determine death rates between countries of different population sizes it is necessary to control for population size in order to calculate a mortality rate per million (pm) population. This is based upon the numbers of deaths in each country of people, in this case, those aged 55-74, divided by that country's 55-74year old population to produce a death rate per million. For example, in 2013-15 in the UK the average numbers of CDD of 55-74year- olds was 34,219. There was an average population of 13.556 million in the age-band 55-74, 
so divide the numbers of deaths by the numbers in the population gives a CDD rate of $2524 \mathrm{pm}$. The WHO Age-Standardised-DeathRates is however based upon total population and standardised for world population [1]. One statistical problem when comparing between countries of difference population sizes is how to measure between them as one cannot use actual numerical data. However, by transforming the data into rates that controls for population it is possible to make statistical comparisons between the countries using both confidence intervals and chi square tests, only the former is used in this study. This approach has been utilised in a range of other international studies in major journals related to child mortality, cancer and neurological outcomes $[15,18,20]$.

\section{Result}

Reducing CDD: Table 1 lists the CDD rates for people aged-5574 and the percent of change between 1989-91 to 2013-15 and Confidence Intervals used to explore any significant difference between the UK and each country's outcomes, controlled for age and population. The highest current rate being the USA at 3440 per million (pm) followed by Finland 3197pm and Greece 3173pm. In 1989-91 the UK rate at $9269 \mathrm{pm}$ was fourth highest but now at $2524 \mathrm{pm}$ it has fallen to being ninth highest, equivalent to a $73 \%$ reduction, the fourth largest fall over the period. The lowest rates were in France 1522pm, Australia 1634pm and Japan 1866pm.

In 1989-91 the OWC average, minus the UK, had been $6825 \mathrm{pm}$ falling to $2328 \mathrm{pm}$ by $2013-15$ which is equivalent to a fall of $66 \%$ over the period. Only Norway falling $78 \%$ and Australia and Ireland declining by $75 \%$ had bigger reductions than the UK's $73 \%$ fall. Using confidence intervals to compare between UK and the OWC found that Australia, Ireland and Norway had significant bigger falls in CDD than the UK, but Britain had significantly bigger reductions than sixteen countries, including France, Germany and the USA (insert Table 1).

Table 1: CDD (55-74) rates per million population. Confidence Intervals Compares UK to Other Western Countries 1989-91 v 2013-15. Ranked by highest current rates.

\begin{tabular}{|c|c|c|c|c|}
\hline Country \& Years Current Ranks & ASD Rates & $\%$ of Change & Lower & Upper \\
\hline \multirow{2}{*}{ 1. USA 1989-91 2013-15 } & 9589 & \multirow{2}{*}{$-65 \%$} & \multirow{2}{*}{1.24} & \multirow{2}{*}{1.4} \\
\hline & 3440 & & & \\
\hline \multirow{2}{*}{ 2. Finland 1989-91 2013-15 } & 9563 & \multirow{2}{*}{$-67 \%$} & \multirow{2}{*}{1.16} & \multirow{2}{*}{1.3} \\
\hline & 3197 & & & \\
\hline \multirow{2}{*}{ 3.Greece 1989-91 2013-15 } & 6378 & \multirow{2}{*}{$-50 \%$} & \multirow{2}{*}{1.72} & \multirow{2}{*}{1.94} \\
\hline & 3173 & & & \\
\hline \multirow{2}{*}{ 4. Germany 1990-92 2013-15 } & 7227 & \multirow{2}{*}{$-58 \%$} & \multirow{2}{*}{1.45} & \multirow{2}{*}{1.64} \\
\hline & 3032 & & & \\
\hline \multirow{2}{*}{$\begin{array}{l}\text { 5. Austria 1989-91 Austria 2013- } \\
15\end{array}$} & 7293 & \multirow{2}{*}{$-62 \%$} & \multirow{2}{*}{1.32} & \multirow{2}{*}{1.49} \\
\hline & 2784 & & & \\
\hline \multirow{2}{*}{ 6. Ireland 1989-91 2012-14 } & 10162 & \multirow{2}{*}{$-75 \%$} & \multirow{2}{*}{0.87} & \multirow{2}{*}{$0.98 \#$} \\
\hline & 2553 & & & \\
\hline \multirow{2}{*}{ 7. Sweden 1989-91 2013-15 } & 6969 & \multirow{2}{*}{$-64 \%$} & \multirow{2}{*}{1.26} & \multirow{2}{*}{1.42} \\
\hline & 2539 & & & \\
\hline \multirow{2}{*}{ 8. UK $1989-91$ 2013-15 } & 9264 & \multirow{2}{*}{$-73 \%$} & 1 & 1 \\
\hline & 2524 & & 1 & 1 \\
\hline a Portural 100901201214 & 7245 & $600 \%$ & 107 & 122 \\
\hline 9. Portugal $1989-912012-14$ & 2253 & $-69 \%$ & 1.07 & 1.22 \\
\hline & 8296 & & & \\
\hline 10. New Zealand 1989-91 2011-13 & 2370 & $-72 \%$ & 0.98 & $1.12 \mathrm{n} . \mathrm{s}$ \\
\hline 11 Polgium 1009-01 2012 15 & 5538 & $600 \%$ & 127 & 156 \\
\hline 11. Belgium 1989-91 2013-15 & 2208 & $-60 \%$ & 1.37 & 1.56 \\
\hline 12 Donmorl 100001201215 & 6968 & 6006 & ז & 1 0 \\
\hline 12. Denmark 1989-91 2013-15 & 2129 & $-69 \%$ & 1.05 & 1.2 \\
\hline 12 Itoly $1000012012-15$ & 5147 & & & \\
\hline 13. Italy 1989-91 2013-15 & 2100 & $-59 \%$ & 1.4 & 1.6 \\
\hline 14 Conadr 100001201112 & 5892 & $650 \%$ & $121+2+3$ & 120 \\
\hline 14. Lanada 1989-912011-13 & 2077 & $-65 \%$ & 1.21 & 1.38 \\
\hline 15 Nethorland 1000 012012,15 & 6478 & $600 \%$ & 106 & 121 \\
\hline 15. Necherrand $1909-912013-15$ & 2004 & $-69 \%$ & 1.06 & 1.21 \\
\hline 16 Cnoin 100001201215 & 4715 & 6000 & 120 & 150 \\
\hline 16. spain 1989-91 2013-15 & 1899 & $-60 \%$ & 1.38 & 1.58 \\
\hline
\end{tabular}




\begin{tabular}{|c|c|c|c|c|}
\hline \multirow{2}{*}{ 17. Switzerland 1989-91 2013-15 } & 4083 & \multirow{2}{*}{$-54 \%$} & \multirow{2}{*}{1.41} & \multirow{2}{*}{1.63} \\
\hline & 1884 & & & \\
\hline \multirow{2}{*}{ 18. Norway 1989-91 2013-15 } & 8395 & \multirow{2}{*}{$-78 \%$} & \multirow{2}{*}{0.76} & \multirow{2}{*}{$0.87 \#$} \\
\hline & 1867 & & & \\
\hline \multirow{2}{*}{ 19. Japan 1989-91 2013-15 } & 3589 & \multirow{2}{*}{$-48 \%$} & \multirow{2}{*}{1.78} & \multirow{2}{*}{2.05} \\
\hline & 1866 & & & \\
\hline \multirow{2}{*}{ 20. Australia 1989-91 2013-15 } & 6708 & \multirow{2}{*}{$-75 \%$} & \multirow{2}{*}{0.84} & \multirow{2}{*}{$0.97 \#$} \\
\hline & 1654 & & & \\
\hline \multirow{2}{*}{ 21. France 1989-91 2012-14 } & 3825 & \multirow{2}{*}{$-60 \%$} & \multirow{2}{*}{1.36} & \multirow{2}{*}{1.57} \\
\hline & 1522 & & & \\
\hline
\end{tabular}

${ }^{*}$ Not significant $=$ n.s Country significantly better UK $=$ \#

Table 2 presents total CDD rates, the Age-Standardised-DeathRates and Confidence Intervals used to examine any significant difference between the UK and each country's outcomes, controlled for age and population.

The current highest rate was Greece at $1414 \mathrm{pm}$, followed by Germany $1400 \mathrm{pm}$ and Austria $1360 \mathrm{pm}$. The current average ASDR for the OWC was $1023 \mathrm{pm}$, a fall equivalent to $58 \%$ over the period. The UK who had been seventh highest in 1989-91, at $2740 \mathrm{pm}$, in $2013-15$ are now eleventh highest at $1010 \mathrm{pm}$, which is a $63 \%$ fall, which was the second biggest reduction over the period. No country had significantly greater falls than the UK over the period, but Britain reduced CDD more than fifteen countries, including France, Germany and the USA (insert Table 2).

Table 2: Age-Standardised-Death-Rates CDD rates per million population 1989-91 v 2013-15. Confidence Intervals Compare UK to Other Western Countries. Ranked by highest current rates.

\begin{tabular}{|c|c|c|c|c|}
\hline Country \& Years Current Ranks & ASD Rates & $\%$ of Change & Lower & Upper \\
\hline \multirow{2}{*}{ 1. Greece 1989-91 2013-15 } & 2745 & \multirow{2}{*}{$-48 \%$} & \multirow{2}{*}{1.27} & \multirow{2}{*}{1.54} \\
\hline & 1414 & & & \\
\hline \multirow{2}{*}{ 2. Germany 1989-91 2013-15 } & 2849 & \multirow{2}{*}{$-51 \%$} & \multirow{2}{*}{1.21} & \multirow{2}{*}{1.47} \\
\hline & 1400 & & & \\
\hline \multirow{2}{*}{ 3. Austria 1989-91 2013-15 } & 2964 & \multirow{2}{*}{$-54 \%$} & \multirow{2}{*}{1.13} & \multirow{2}{*}{1.37} \\
\hline & 1360 & & & \\
\hline \multirow{2}{*}{ 4. Finland 1989-91 2013-15 } & 3070 & \multirow{2}{*}{$-57 \%$} & \multirow{2}{*}{1.07} & \multirow{2}{*}{1.29} \\
\hline & 1329 & & & \\
\hline \multirow{2}{*}{ 5. USA 1989-91 2013-15 } & 2450 & \multirow{2}{*}{$-46 \%$} & \multirow{2}{*}{1.33} & \multirow{2}{*}{1.62} \\
\hline & 1326 & & & \\
\hline \multirow{2}{*}{ 6. Ireland 1989-91 2012-14 } & 3164 & \multirow{2}{*}{$-62 \%$} & \multirow{2}{*}{0.93} & \multirow{2}{*}{$1.13 \mathrm{n} . \mathrm{s}$} \\
\hline & 1199 & & & \\
\hline \multirow{2}{*}{ 7. New Zealand 1989-91 2011-13 } & 2628 & \multirow{2}{*}{$-55 \%$} & \multirow{2}{*}{1.1} & \multirow{2}{*}{1.34} \\
\hline & 1176 & & & \\
\hline \multirow{2}{*}{ 8. Sweden 1989-91 2013-15 } & 2492 & \multirow{2}{*}{$-55 \%$} & \multirow{2}{*}{1.11} & 125 \\
\hline & 1124 & & & 1.35 \\
\hline a Portural 1909-01 2012,14 & 2873 & $620 \%$ & 092 & $112 \mathrm{nc}+2$ \\
\hline 9. Portugal 1909-91 2012-14 & 1081 & $-0<\%$ & 0.92 & 1.1311 .5 \\
\hline 10 Italy $1089-012012-15$ & 2254 & $520 \%$ & 117 & 143 \\
\hline 10. 1taly 1989-91 2013-15 & 1076 & $-5<\%$ & 1.17 & 1.43 \\
\hline 11 UK 1989-91 2013-15 & 2740 & $-630 \%$ & 1 & 1 \\
\hline 11. & 1010 & $-05 \%$ & 1 & 1 \\
\hline 12 Rolrium 190901201215 & 2135 & $-53 \%$ & 115 & 141 \\
\hline 12. Belgium 1989-91 2013-15 & 1001 & $-53 \%$ & 1.15 & 1.41 \\
\hline 12 Nothorlond 100001201215 & 2172 & 5606 & 107 & 122 \\
\hline 13. ivetnerrana 1989-91 2013-15 & 955 & $-56 \%$ & 1.07 & 1.32 \\
\hline 14 Norway 1989-91 2013-15 & 2427 & $-61 \%$ & 0.94 & $116 \mathrm{~ns}$ \\
\hline 14. Norw dy $1909-912013-13$ & 937 & $-01 \%$ & 0.94 & 1.1011 .5 \\
\hline & 2099 & $-560 \%$ & 107 & 132 \\
\hline 15. Switzerland 1989-91 2013-15 & 921 & $-56 \%$ & 1.07 & 1.32 \\
\hline
\end{tabular}




\begin{tabular}{|c|c|c|c|c|}
\hline \multirow{2}{*}{ 16. Denmark 1989-91 2013-15 } & 2323 & \multirow{2}{*}{$-61 \%$} & \multirow{2}{*}{0.96} & \multirow{2}{*}{$1.19 \mathrm{n} . \mathrm{s}$} \\
\hline & 915 & & & \\
\hline \multirow{2}{*}{ 17. Canada 1989-91 2011-13 } & 2056 & \multirow{2}{*}{$-57 \%$} & \multirow{2}{*}{1.05} & \multirow{2}{*}{1.31} \\
\hline & 889 & & & \\
\hline \multirow{2}{*}{ 18. Spain 1989-91 2013-15 } & 2134 & \multirow{2}{*}{$-58 \%$} & \multirow{2}{*}{1.01} & \multirow{2}{*}{1.25} \\
\hline & 887 & & & \\
\hline \multirow{2}{*}{ 19. Australia 1989-91 2013-15 } & 2430 & \multirow{2}{*}{$-65 \%$} & \multirow{2}{*}{0.87} & \multirow{2}{*}{$1.08 \mathrm{n} . \mathrm{s}$} \\
\hline & 871 & & & \\
\hline \multirow{2}{*}{ 20. Japan 1989-91 2013-15 } & 1663 & \multirow{2}{*}{$-55 \%$} & \multirow{2}{*}{1.09} & \multirow{2}{*}{1.36} \\
\hline & 746 & & & \\
\hline \multirow{2}{*}{ 21. France 1989-91 2012-14 } & 1545 & \multirow{2}{*}{$-52 \%$} & \multirow{2}{*}{1.16} & \multirow{2}{*}{1.46} \\
\hline & 741 & & & \\
\hline
\end{tabular}

${ }^{*}$ Not significant $=$ n.s.

\section{\%GDPHE economic input into health}

Table 3 ranks the countries by the highest average \%GDPHE for 1980-2015. The current highest \%GDPEH is the USA at $16.8 \%$ followed by Switzerland 12.1\% and Germany 11.2\% 11.5\% down to the lowest which were Ireland at 7.8\%, Greece $8.4 \%$, Spain $9.2 \%$, with Britain at $9.9 \%$ was thirteenth highest. The average for the period 1980-2015 ranged from the USA $13.39 \%$, Germany $10.12 \%$ and Switzerland $10.09 \%$ down to the lowest for the period which was the UK at $7.6 \%$ followed by Greece $6.68 \%$ and Spain $7.72 \%$. Comparing the average UK \%GDPEH with the OWC, yields a ratio of
1:1.18. Whilst over the years all countries increased their \%GDPEH but occasionally there would be a fall of \%GDPHE from the previous year. For example, there were falls in the UK from the previous year's \%GDPEH in 1984, 1985 and 1987, again in 1994 and 1997 and then in 2011, 2013 before reaching its highest ever at 9.9\% in 2015 but still below the OWC average of $10.8 \%$. It is noteworthy that of the top ten average \%GDPEH countries comparing the UK average with the other top ten spending countries was more than 1:1.15, indeed the UK to USA ratio was $1: 1.76$ and for France, Germany and Switzerland was 1:1.33. (insert Table 3)

Table 3: Total \% Gross-Domestic-Product Expenditure on Health 1980 -2000-2015 (Countries missing years in brackets). UK to Other Country Average \%GDPEH ratio. Ranked by \%GDPEH Average.

\begin{tabular}{|c|c|c|c|c|c|c|}
\hline Country \& Rank & Total GDP 1980 & Total GDP 2000 & Total GDP 2010 & Total GDP 2015 & $\begin{array}{c}\text { Total Average } \\
1980-15\end{array}$ & UK to OWC Ratio \\
\hline 1. USA & 9 & 13.4 & 17.1 & 16.8 & 13,39 & 01:01.8 \\
\hline 2.Germany [1] & 8.4 & 10.1 & 11.6 & 11.2 & 10.12 & 01:01.3 \\
\hline 3.Switzerland & 7.3 & 10.2 & 10.9 & 12.1 & 10.09 & 01:01.3 \\
\hline 4. France & 7 & 10.3 & 11.6 & 11.1 & 10.08 & 01:01.3 \\
\hline 5. Canada & 7 & 8.8 & 11.1 & 10.4 & 9.8 & 01:01.3 \\
\hline 6. Netherlands & 7.4 & 8 & 12.1 & 10.7 & 9.03 & 01:01.2 \\
\hline 7.Belgium [1] & 6.3 & 9 & 10.6 & 10.5 & 8.96 & 01:01.2 \\
\hline 8. Austria [2] & 7.4 & 9 & 11.1 & 10.3 & 8.87 & 01:01.2 \\
\hline 9. Sweden & 8.9 & 8.2 & 9.5 & 10 & 8.77 & 01:01.1 \\
\hline 10. Denmark [1] & 8.9 & 8.3 & 11.1 & 10.3 & 8.76 & 01:01.1 \\
\hline 11. Norway & 7 & 8.4 & 9.4 & 10 & 8.47 & 01:01.1 \\
\hline 12.Australia [2] & 6.1 & 8 & 8.9 & 9.4 & 8.43 & 01:01.1 \\
\hline 13. New Zealand & 5.9 & 7.7 & 10 & 9.3 & 8.34 & 01:01.1 \\
\hline 14. Finland & 6.3 & 7.2 & 9 & 9.4 & 8.27 & 01:01.1 \\
\hline 15. Japan [2] & 6.5 & 7.7 & 9.6 & 10.9 & 8.23 & 01:01.1 \\
\hline 16. Italy & 7 & 8.1 & 9.4 & 9 & 8.12 & 01:01.1 \\
\hline 17. Portugal [1] & 5.3 & 8.8 & 10.9 & 9 & 8.09 & 01:01.1 \\
\hline 18. Ireland & 8.2 & 6.1 & 9.2 & 7.8 & 8.05 & 01:01.1 \\
\hline 19. Spain & 5.3 & 7.2 & 9.6 & 9.2 & 7.72 & 01:01.0 \\
\hline 20. Greece [3] & 5.9 & 7.9 & 9.5 & 8.4 & 7.68 & 01:01.0 \\
\hline 21. U.K & 5.6 & 7 & 9.4 & 9.9 & 7.6 & 01:01.0 \\
\hline OWC (-UK) average & 7.1 & 8.6 & 10.4 & 10.8 & 8.96 & 01:01.2 \\
\hline UK:OWC ratios & 1.27 & 1.23 & 1.11 & 1.09 & 1.18 & 01:01.2 \\
\hline
\end{tabular}




\section{Discussion}

The problem with international mortality studies can be the issue of diagnosis. However, this is minimized by analyzing whole diagnostic category data from the world's most consistent and uniform database, WHO mortality statistics [1]. This study indicates that between 1989-91 and 2013-15, across the Western world, there had been an average fall the equivalent of almost two-thirds in CDD of people aged 55-74. With slightly lower reductions in total CDD all age ASDR. This reflects well on the cardiovascular services and in terms of \%GDPEH, money well spent and should be a boost to the moral of patents, families and those in the cardiac services, especially in the United Kingdom. Such results should be known more widely to patients. Whilst cancers deaths in the Western countries are down in the 55-74 age-band, the cardiac services in every country under review have had an even bigger reduction in mortality of people aged 55-74 [18] substantially contributing to avoiding early death and disability and improved life-expectancy.

What might have accounted for these general changes? Is this an indication of the effects of reduction of smoking [12]? Though the issue of increased obesity is a problem for future outcomes as obesity and CDD are linked $[7,21,22]$. It is feared that we may well see a reverse of these good CDD results in the coming years because of rises in obesity and type 2 diabetes in many Western countries $[23,26]$. Recent WHO data on insufficient physical exercise of younger people throughout the Western world, raises the question can the improvement be maintained [22,27]. One positive factor might be the International Tobacco Control efforts over past decades $[11,23,28]$ but in a 15 country study, including the UK, Britain's results were close to the overall average fall in smoking, as well as other public health approaches [10,11,22,23,26-30], so this does not seem primarily to be an explanation for the UK significantly improved outcomes.

What can account for the comparative UK success? Speculating on possible reasons for the UK's CDD greater reductions may at least in part, be related to two major well-funded government pan-national policies regarding CDD. Firstly, the "National Service Framework for Coronary Heart Disease" published in 2000 established a 10year strategy with the aim of reducing coronary heart disease related death across the UK [31] The main features of this policy were (a) to set out formal standards of care which local health authorities were expected to achieve, (b) help NHS organisations focus on clinically and cost-effective treatment strategies to achieve this aim, and (c) encourage health professionals in primary and secondary care to work in a collaborative fashion.

This policy was further supplemented by the pan-UK adoption of primary percutaneous coronary intervention for the treatment of ST-elevation myocardial infarction in 2005, which further reduced the rate of mortality in this patient population. Secondly, "The National Service Framework for Long-term Conditions" published in 2005 established quality requirements to transform health and social care service support for people with long-term neurological conditions including those presenting with acute neurological conditions such as stroke [32]. These pan-national quality requirements included early access to appropriate neurological care including brain imaging and thrombolysis, early and specialist rehabilitation, community rehabilitation and support as well as provision of personal care and support. This said however, this study cannot fully account for the British cardiac success other than to note they achieved more with proportionally less.

The UK's significantly bigger reductions of CDD of people aged 55-74 than sixteen OWC, including the USA, is striking. Indeed, it might be asked what the USA is doing wrong compared with the other Western countries. Nonetheless these results counter the somewhat pessimistic media view of the NHS, and it should be remembered that $\mathrm{CDD}$ constitutes the highest mortality rate for people in this age-band. Thus, major falls in UK CDD may be an explanation for an earlier result that found that the UK had substantial bigger reductions in total adult (55-74) mortality rates than eighteen of the other twenty countries [19]. As CDD is the largest single mortality category this success of the UK cardiology services will have made a major contribution to the saving of lives and improving life expectancy. Despite gloomy discussions over budget money for the NHS, our findings show that the UK has made great strides and comparatively greater than the majority of the other countries, including France, Germany and the USA. The question is, with the changing demographics, can this be maintained?

Finally, it is reiterated that this study cannot explain the reasons for the reduced CDD in the various countries, the USA in particular, which will require country-specific research. However, it provides impetus for further research to determine what is the NHS 'doing right' in the field of heart related diseases and for a cautious degree of congratulation? Furthermore, the substantial reduction of CDD is every country under-review should be a boost for the morale of patients and families facing the anxieties surrounding heart disease and merits being widely known, as these successes clearly contribute to the improve in life-expectancy.

\section{References}

1. WHO (2018) Annual Health Statistics.

2. OECD (2017) Health at a Glance.

3. Goa L, Wang Y, Lu Y, Cao F, Chen Y, et al. (2017) Long-term clinical outcomes of successful revascularization with drug-eluting stents for chronic total occlusions: A systematic review and meta-analysis. Cather Cardiovasc Interv 89: 574-581.

4. Xu FQ, Yu RH, Guo JJ, Bai R, Liu N, et al. (2017) Catheter ablation of recurrent paroxysmal atrial-fibrillation: Is gap closure combining ganglionated plexi ablation more effective? Pacing Clin Electrophysiol 40(6): 672-682.

5. Maggioni AP, Calabria S, Rossi E, Martini N (2017) Use of lipid lowering drugs in patients at very high risk of cardiovascular events: An analysis on nearly 3,000,000 Italian subjects of the ARNO observatory. Int J Cardiol 246: 62-67.

6. Mellwig KP, Horstotte D, van Buuren D (2017) Lipoprotein and coronary heart disease- Is there an efficient secondary prevention? Clin Res Cardiol Suppl 12: 18-21.

7. Grützmacher P, Öhm B, Szymczak S, Dorbath C, Brzoska M, et al. (2017) Primary and secondary prevention of cardiovascular disease in patients with hyperliproteinemia. Clin Res Cardio Supl 12: 22-26.

8. Van der Velde JHPM, Koster A, Van der Berg JD, Sep SJS, Van der Kallen CJH, et al. (2017) Sedentary behaviour, physical activity and fitness: The Maastricht study. Med Sci Sports Exerc 49(8): 1583-1591. 
9. Ke DS (2012) Overwork, stroke and karoshi-death from overwork. Acta Neurologica Taiwan 21: 54-59.

10. Lin RT, Lin CK, Christiani DC, Kawachi I, Cheng Y, et al. (2017) The impact of the introduction of new recognition criteria for overworkrelated cardiovascular and cerebrovascular diseases: A cross-country comparison. Sci Rep 7(1): 167

11. Cronin EM, Kearney PM, Kearney PP, Sullivan P, Perry IJ, et al. (2012) Coronary heart attack Ireland Registry (CHAIR) Working Group. Impact of a national smoking ban on hospital admission for acute coronary syndromes: A longitudinal study. Clin Cardiol 5: 205-209.

12. Lin H, Wang H, Wu W, Lang L, Wang G, et al. (2013) The effects of smokefree legislation on acute myocardial infarction: Systematic review and meta-analysis. BMC Pub Health 31: 529-539.

13. Ouwerkerk W, Voors AA, Anker SD, Cleland JG, Dickstein K, et al. (2017) Determinant and clinical outcome of uptitration of ACE-inhibitors and beta-blockers -blockers in patients with heart failure: a prospective European study. Eur Heart J.

14. Paola Ballotari, Francesco Venturelli, Marina Greci, Paolo Giorgi Rossi, Valeria Manicardi, et al. (2017) Sex differences in the effect of Type 2 Diabetes on major cardiovascular diseases: Results from a populationbased study in Italy. Int J Endocrinol: 6039356.

15. Pritchard C, Rosenorn-Lanng E, Silk A, Hansen L (2017) Controlled Population-Based Comparative Study of USA and International Adult [55-74] Neurological Deaths 1989-2014. Acta Neurol Scand 136: 698707.

16. World Bank (2018) GDP Expenditure on Health.

17. Harding AJE, Pritchard C (2016) UK and Twenty Comparable Countries GDP Expenditure-on-Health 1980-2013: The Historic and Continued Low Priority of UK Health Related Expenditure. Int J Health Pol Manage 5: $1-5$.

18. Pritchard C \& Hickish T (2011) Comparing cancer mortality rates in England \& Wales with other major developed countries 1979-2006. British Journal of Cancer 105(11): 1788-1994.

19. Pritchard C, Rosenorn-Lanng E, Hickish T, Wallace MSW (2016) Population Based Study Comparing UK and 20 Western countries efficiency in reducing adult (55-74) Cancer and Total Mortality rates 1989-2010: cause for cautious celebration? Journal Royal Society Medicine Open 7(6): 2054270416635036.

20. Pritchard C, Mirza S (2016) Under-fives Child Mortality and ChildAbuse-Related-Deaths in the Former USSR: Is there an Under-reporting of Abuse related deaths? Child Abuse Review 25: 218-229.
21. Allen K, Gillespie DO, Guzman-Castillo M, Diggle PJ, Capewell S, et al (2016) Future trends and inequalities in premature coronary deaths in England: Modelling study. Int J Cardiol 15: 290-297.

22. Gillespie DO, Allen K, Guzman-Castillo M, Bandosz P, Moreira P, et al. (2015) The Health Equity and Effectiveness of Policy Options to Reduce Dietary Salt Intake in England: Policy Forecast. PLoS One 10(7): e0127927.

23. Capewell S, Capewell A (2018) An effectiveness hierarchy of preventive interventions: neglected paradigm or self-evident truth? J Public Health (Oxf) 40(2): 350-358

24. Friesling H, Arnold M, Soerjomaram I, O Doherty MG, Ordonez-Mena JM, et al. (2017) Comparison of general obesity and measures of body fat distribution in older adults in relation to cancer risk; meta-analysis of individual participant data of seven prospective cohorts in Europe. Br J Cancer 116: 1486-1497.

25. Cheng FW, Gao X, Bao L, Mitchell Dc, Woos C, et al. (2017) Obesity as a risk factor for developing functional limitation among older adults: A controlled inference tree analysis. Obesity 25(7): 1263-1269.

26. Hitchman SC, Fong GT, Zanna MP, Thrasher JF, Chung-Hall J, et al. (2014) Socioeconomic status and smokers' number of smoking friends: findings from the International Tobacco Control (ITC) Four Country Survey. Drug Alcohol Depend 143: 158-166.

27. Gutholt R, Stevens GA, Riley LM, Bull FC (2018) World-wide survey of insufficient physical activity from 2001-2016: a pooled analysis of 358 surveys with 1.9 million participants. Lancet Global Health.

28. Timmis A, Gale CP, Flather M, Maniadakis N, Vardas P, et al. (2018) Cardiovascular Disease Statistics From the European Atlas: Inequalities Between High and Middle Income Member Countries of the ESC. Eur Heart J Qual Care Clin Outcomes 4(1): 1-3.

29. Guzman-Castillo M, Ahmed R, Hawkins N, Scholes S, Wilkinson E, et al. (2015) The contribution of primary prevention medication and dietary change in coronary mortality reduction in England between 2000 and 2007: a modelling study. BMJ Open 5(1): e006070.

30. Peñalvo JL, Cudhea F, Micha R, Rehm CD, Afshin A, et al. (2017) The potential impact of food taxes and subsidies on cardiovascular disease and diabetes burden and disparities in the United States. BMC Med 15(1): 208.

31. National Service Framework (2000) Coronary Heart Disease.

32. Dept of Health (2005) The National Service Framework for Long-term Conditions HMSO, London. 